\title{
An Unusual Presentation of a Child with Scurvy: A Case Report
}

\author{
BS Mahapatra', Suneeta Padhy ${ }^{2}$ \\ ${ }^{1}$ Senior Consultant Pediatrician, Imperial Medicare Center, Maldives. \\ ${ }^{2}$ Consultant Pathologist, Indira Gandhi Memorial Hospital, Maldives. \\ DOI: https://doi.org/10.24321/2394.6539.202106
}

\section{I $\quad \mathbf{N} \quad \mathbf{F} \quad \mathbf{O}$}

\section{Corresponding Author:}

BS Mahapatra, Imperial Medicare Center, Maldives, Andman and Nicobar, India.

E-mail Id:

mb_sankar@hotmail.com

Orcid Id:

https://orcid.org/0000-0002-0117-6951

How to cite this article:

Mahapatra BS, Padhy S. An Unusual Presentation of a Child With Scurvy: A Case Report. J Adv Res

Med Sci Tech. 2021;8(2):12-14.

Date of Submission: 2021-03-17

Date of Acceptance: 2021-06-25

\section{$\begin{array}{lllllllllllllll}\mathbf{A} & \mathbf{B} & \mathbf{S} & \mathbf{T} & \mathbf{R} & \mathbf{A} & \mathbf{C} & \mathbf{T}\end{array}$}

Nutritional deficiency is very common in pediatric patients, especially in developing countries. A 4-year-old Maldivian boy presented with pain in major joints of lower limbs since two months and was unable to stand and walk since one month. There was no history of fever or fall. The growth was average with mild pallor. There was no joint swelling. Xray knee joint showed epiphyseal separation, cortical thinning suggesting a radiological diagnosis of Scurvy and after Vit $C$ supplementation the child showed clinical and radiological improvement in two weeks. So, a high index of suspicion is required for early diagnosis and treatment.

Keywords: Scurvy, Vitamin C, Osteopenia, Pseudoparalysis

\section{Introduction}

For the paediatric patient who presents with multiple bone and joint pains, the diagnosis usually rests among rickets, juvenile rheumatoid arthritis and reactive arthritis. ${ }^{1}$ Being a pediatrician, we should ask for history of multiple nutritional deficiency especially in developing countries. ${ }^{2}$ Nutritional deficiency can be seen in developed countries also due to peculiar food habits of children. ${ }^{3} \mathrm{~A}$ Maldivian child reported with severe pain in joint and bone especially in lower limbs.

\section{Case Presentation}

History: A 31/2-year-old male child presented in outpatient department with severe pain in joints and bones in lower limb for 2 months followed by inability to walk and stand for 1 month.

The child was apparently well 2 months back. There was a gradual onset of pain in legs without having a history of fever or injury. After 4 weeks, he was unable to stand and walk without support. There was no swelling around any joint. Birth and vaccination history was uneventful. Dietary history was significant as he was mostly fed with fish and meat. Fruit and vegetable intake was not enough. He was treated with analgesic and multivitamins by another Pediatrician and orthopedician.

On Examination: The child was of good build and healthy looking. He was unable to stand and walk. His respiratory and cardiovascular system was normal. On musculoskeletal examination, the upper limb was normal. In lower limb, the joint movement was painful in both ankle and knee joint. There was no visible swelling.

\section{Investigation}

TLC: $8600 \times 103$ N: $45.2 \%$ L: $47.3 \%$

Hb: 11.4gm\% Platelet: 403x103 ESR: 27/mm

Blood Picture: Microcytic hypochromic with mild lymphopenia.

Vit D: 50.12 iu

Cal: 10.1 
CRP: 3.8

\section{S. Urea: 24.5}

Creatinin: 0.3

LFT: Within normal limit

Vit C: $1.69 \mathrm{mg} / \mathrm{dl}$

Xray both Knee Joint: Ground glass osteoporosis, thinning of cortex especially around epiphysis (Ring sign) of both Femora and Tibiae. Findings were suggestive of Vit C deficiency (Scurvy).

\section{Before}

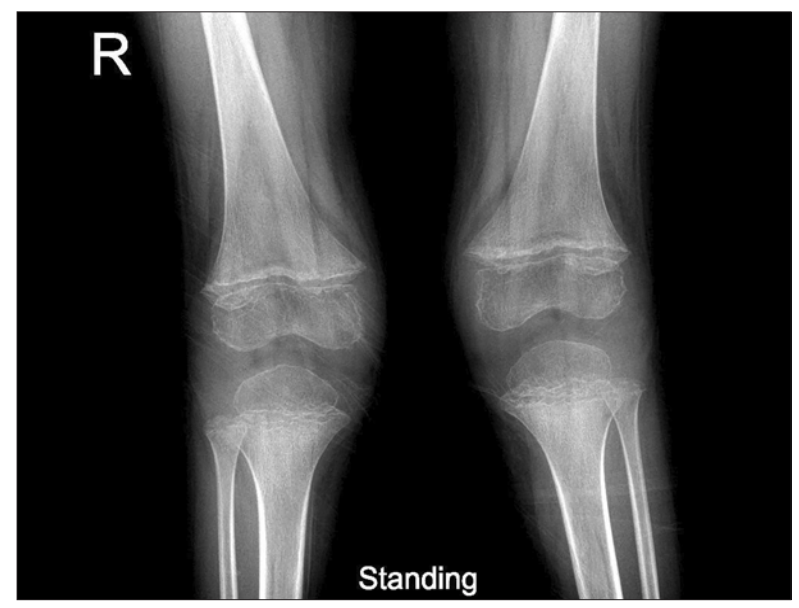

\section{After}

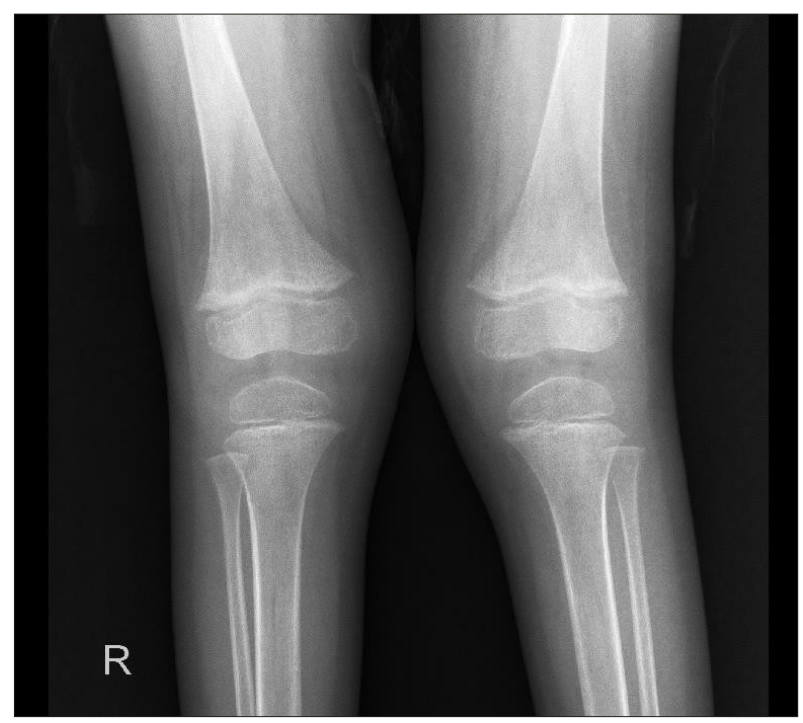

\section{Management}

The child was given a dose of oral Vit C 500 mg daily for a week with supplementation of other multivitamins.

Follow up after 1 week showed marked reduction of pain and improvement in joint movement. The child started walking without support. Repeat X-ray showed healing of epiphyseal features.

\section{Discussion}

In pediatric age, joint pain and swelling with inability to walk always gives suspicion to rheumatoid arthritis, septic arthritis or osteomyelitis. If it is associated with bleeding, it gives suspicion of bleeding disorders like hemophilia or acute leukemia. Scurvy being a rare disorder usually missed by physician leading to a delayed diagnosis. ${ }^{4,5}$ Initial manifestations of scurvy are vague like irritability, lack of appetite. ${ }^{5}$ As it progresses, there will be generalized tenderness especially over long bones due to subperiosteal hemorrhage. Pseudoparalysis may become apparent due to bone pain. ${ }^{5}$ The dominant features of this patient were joint pain and inability to walk without visible joint swelling.

The diagnosis was mostly made on the basis of radiological findings and dietary history with exclusion of juvenile rheumatoid arthritis and septic arthritis through investigation.

Radiological changes in long bones particularly around knee are most diagnostic of scurvy. The bone showed osteopenia. ${ }^{6}$ The epiphysis and periosteum become easily detachable because of subperiosteal hemorrhage. Separation of metaphyseal plate from diaphysis may occur.

In this patient, epiphysial separation was evident in distal femur and proximal tibia. Cortical bone thinning was also seen in long bones which is described as pencil point cortex. Metaphysis showed decreased trabeculae leading to ground glass appearance. The physis showed thickening and sclerosis which is known as Frankel line. The adjacent lucent zone on its diaphyseal side is known as the Zone of Scurvy line. ${ }^{7}$ Both are present in knee X-ray of this patient. Zone of proliferative cartilage cell is distorted producing spicules from metaphysis. The zone of temporary calcification broadens producing a wide radio opaque metaphyseal band. Metaphyseal beaks called as pelcan spurs are associated with healing features at the periphery of zone of calcification. ${ }^{8}$ Costochondral junctions expand and become round, smooth, knobby which simulate ricket. Because of anemia, there would be marrow hyperplasia which causes hair-on-end appearance. During healing phase, subperiosteal hemorrhage occurs with loss of scurvy line.

So, diagnosis is based on clinical and radiological findings. A dietary history will be compatible with diagnosis. ${ }^{9}$ Serum or plasma vit c does not correlate with tissue level. ${ }^{10}$ Anemia is common with scurvy. ${ }^{11}$ Healing occurs rapidly with oral vit c. The dosage can be reduced to $50 \mathrm{mg} /$ day until complete radiology and clinical improvement has taken place. ${ }^{12}$ The patient showed rapid clinical improvement after 2 weeks and was able to stand and walk without support.

\section{Conclusion}

An index of suspicion with detailed dietary history is 
important for prompt and early diagnosis of scurvy. It can happen in pediatric age group in spite of ready availability of fruits and vegetables mainly due to peculiar food habits.

\section{Conflict of Intrest: None}

\section{References}

1. Kimura $Y$, Southwood TR. Evaluation of the child with joint pain or swelling. 2010 [cited 2021 June 5]. Available from: http://www.uptodate.com/.

2. Bari A, Javaid BK, Rehman S, Naz S. Scurvy: presenting as musculoskeletad pain. J Coll Physicians Surg Pak. 2009;19(3):198-200. [PubMed] [Google Scholar]

3. Algahtani HA, Abdu AP, Khojah IM, Al-Khathaami AM. Inability to walk due to scurvy: a forgotten disease. Ann Saudi Med.2010;30(4):325-328. [PMC free article] [PubMed] [Google Scholar]

4. Ratanachu-Ek S, Jeerathanyasakun Y, Sukswai P, Wongtapradit L. Scurvy in pediatric patients: a review of 28 cases. J Med Assoc Thai. 2003;86:S734-S740. [PubMed] [Google Scholar]

5. Riepe FG, Eichmann D, Oppermann HC, Schmitt HJ, Tunnessen WW. Picture of the month. Arch Pediatr Adolesc Med. 2001;155(5):607-8. [PubMed] [Google Scholar]

6. Kotamasu SR. Metabolic bone diseases. In: Kuhn PJ, Slovis TL, Heller JO, editors. Caffey's Pediatric Diagnostic Imaging. 10th edition. Philadelphia, Pa, USA: MosbyElsevier; 2004. pp. 2242-68. [Google Scholar]

7. Duggan CP, Westra SJ, Rosenberg AE. Case 23-2007: a 9-year-old boy with bone pain, rash, and gingival hypertrophy. New England J Med. 2007;357(4):330400. [PubMed] [Google Scholar]

8. Weinstein $\mathrm{M}, \mathrm{Babyn} \mathrm{P}, \mathrm{Zlotkin} \mathrm{S}$. An orange a day keeps the doctor away: scurvy in the year 2000. Pediatrics. 2001;108(3):E55. [PubMed] [Google Scholar]

9. Fain O. Musculoskeletal manifestations of scurvy. Joint Bone Spine. 2005;72(2):124-8. [PubMed] [Google Scholar]

10. Emadi-Konjin P, Verjee Z, Levin AV, Adeli K. Measurement of intracellular vitamin Clevels in human lymphocytes by reverse phase high performance liquid chromatography (HPLC) Clin Biochem. 2005;38(5):450-6. [PubMed] [Google Scholar]

11. Cohen SA, Paeglow RJ. Scurvy: an unusual cause of anemia. J Am Board Fam Pract. 2001;14(4):314-6. [PubMed] [Google Scholar]

12. Levine M, Conry-Cantilena C, Wang Y, Welch RW, Washko PW, Dhariwal KR, Park JB, Lazarev A, Graumlich JF, King $\mathrm{J}$, Cantiline LR. Vitamin C pharmacokinetics in healthy volunteers: evidence for a recommended dietary allowance. Proc Natl Acad Sci USA. 1996;93(8):37049. [PMC free article] [PubMed] [Google Scholar] 